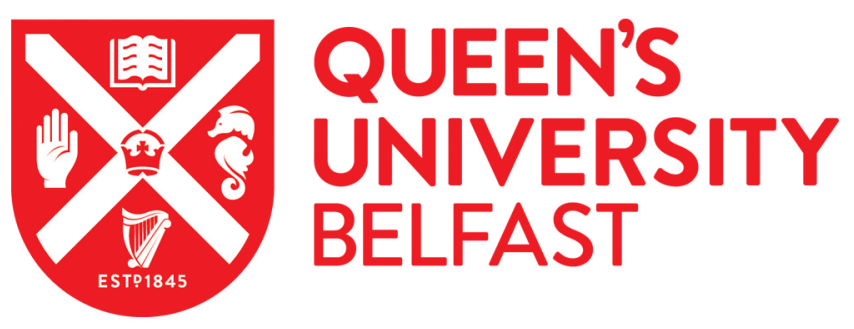

\title{
Providing Optimal Palliative Care for Persons Living with Dementia: A Comparison of Physician Perceptions in the Netherlands and the United Kingdom
}

Brazil, K., Galway, K., Carter, G., \& van der Steen, J. T. (2016). Providing Optimal Palliative Care for Persons Living with Dementia: A Comparison of Physician Perceptions in the Netherlands and the United Kingdom. Journal of Palliative Medicine. https://doi.org/10.1089/jpm.2015.0274

Published in:

Journal of Palliative Medicine

Document Version:

Peer reviewed version

Queen's University Belfast - Research Portal:

Link to publication record in Queen's University Belfast Research Portal

Publisher rights

Final publication is available from Mary Ann Liebert, Inc., publishers http://dx.doi.org/10.1089/jpm.2015.0274

\section{General rights}

Copyright for the publications made accessible via the Queen's University Belfast Research Portal is retained by the author(s) and / or other copyright owners and it is a condition of accessing these publications that users recognise and abide by the legal requirements associated with these rights.

Take down policy

The Research Portal is Queen's institutional repository that provides access to Queen's research output. Every effort has been made to ensure that content in the Research Portal does not infringe any person's rights, or applicable UK laws. If you discover content in the Research Portal that you believe breaches copyright or violates any law, please contact openaccess@qub.ac.uk. 
Title: Providing optimal palliative care for persons living with dementia: a comparison of physician perceptions in the Netherlands and the United Kingdom

Authors:

Kevin Brazil, PhD ${ }^{1}$,

Karen Galway, BSc, MSc, PhD ${ }^{1}$

Gillian Carter, BSc, BSc, $\mathrm{PhD}^{1}$,

Jenny T van der Steen, $\mathrm{PhD}^{2}$

Corresponding Author:

Kevin Brazil

Professor of Palliative Care

School of Nursing and Midwifery

Queen's University Belfast

Medical Biology Centre

97 Lisburn Road

Belfast

BT9 7BL

Tel: +44 (0)2890975782

Email:k.brazil@qub.ac.uk

Affiliations:

1 School of Nursing and Midwifery, Queen's University Belfast, United Kingdom

2 Leiden University Medical Center Department of Public Health and Primary Care, Leiden, The Netherlands; Radboud University Medical Center, Department of Primary and Community Care, Nijmegen, The Netherlands

\section{Acknowledgements}

The authors would like to thank all the GPs who participated in this survey.

Funding was provided by the Care to Know Centre, Ontario, Canada and by the Aspasia supplement to a career award for JTS provided by the Netherlands Organisation for Scientific Research (NWO; Innovational Research Incentives Scheme) Vidi grant number 91711339.

Word Count

Main text $=2616$

Abstract $=235$ 


\section{Abstract}

Background: The European Association for Palliative Care (EAPC) recently issued a framework that defines optimal palliative care in dementia. However implementation of the guidelines may pose challenges for physicians working with dementia patients in practice.

Objective: To measure and compare the perceptions of physicians in two European regions regarding the importance and challenges of implementing recommendations for optimal palliative care in dementia patients.

Design: Cross sectional observational

Setting: The Netherlands and United Kingdom

Subjects: Physicians ( $n=317)$ providing palliative care to patients with dementia Measurements: Postal survey

Results: Physicians in the Netherlands and Northern Ireland (NI), United Kingdom prioritised the same domains of optimal palliative care for dementia, and these match the priorities in the EAPC endorsed guidelines. Respondents in both countries rated lack of education of professional teams and lack of awareness of the general public among the most important barriers to providing palliative care in dementia. $\mathrm{NI}$ respondents also identified access to specialist support as a barrier. The results indicate that there is a strong consensus amongst experts, elderly care physicians and general practitioners, across a variety of settings in Europe, that person centered care involving optimal communication and shared decision-making is the top priority for delivering optimal palliative care in dementia.

Conclusions: The current findings both support and enhance the new recommendations ratified by the EAPC. To take forward implementation of the EAPC guidelines for palliative care for dementia it will be necessary to assess the challenges more thoroughly at a country-specific level and to design and test interventions that may include systemic changes, to help physicians to overcome such challenges.

\section{Keyword}

Dementia, palliative medicine, general practice, geriatrics, health services for the aged 


\section{Background}

Dementia represents a major worldwide health issue. Prevalence estimates for 2020 currently stand at 48.1 million, and for 2040 they are estimated to reach 90.3 million (1). As there is no cure for dementia it is regarded as a terminal condition where survival time ranges from 3 to 10 years $(2,3)$.

A palliative care approach applied to the care for the person living with dementia fits with a disease that is characterised as having progressive functional decline. While palliative care can be applied to all treatment and care in dementia, the evidence indicates that persons living with dementia do not have access to optimal palliative care $(4,5)$. The provision of palliative care for the progression of dementia presents unique challenges. As the disease progresses to the terminal stage, the ability to meaningfully communicate, ambulate or manipulate objects is severely impaired, if not impossible (6), creating significant difficulties for families and physicians providing support.

Structured palliative care standards including advance care planning are a key means of improving care for people nearing the end of life by enabling better planning and provision of care. Although palliative care is a well-developed speciality, it is not integrated within dementia care reinforcing the notion of the need for a dementia-specific approach to the provision of palliative care (7). Responding to this identified need, the European Association for Palliative Care (EAPC) published a research-based position paper that recognised a palliative care approach specific to dementia. The recommendations provided in this report were the product of an exercise that engaged 64 experts from 23 countries resulting in a framework to provide guidance for clinical practice, policy and research. The purpose of this study was threefold: 1) to compare the practice priorities set by experts in the EAPC position paper with what practicing physicians say; 2 ) to report on physicians' perceptions of the challenges of implementing optimal palliative care; and 3) to compare the views of practicing physicians in two different countries (Netherlands and the United Kingdom) with very different structures, contexts, training and experience caring for people with dementia. 


\section{Methods}

\section{Design}

A cross-sectional postal survey was conducted in the United Kingdom (UK) and the Netherlands. Survey responses were received between May and December 2013. In the Netherlands three mail contacts was employed, while in the UK up to four mail contacts was implemented (8). We assured respondents confidentiality in processing of the answers. To maximize responses an incentive of a prize draw for an iPad mini in the UK and gift cards of a similar value in the Netherlands were offered.

\section{Participants}

We selected physicians that assumed primary responsibility for the care of persons with dementia often for years and including at the end of life. In the Netherlands, these were elderly care physicians who are certified after a 3-year specialty training in the field of geriatric disorders and the specific appearances of diseases and disorders in elderly people. (9). They are responsible for care of nursing home residents and part of the care for dementia patients in residential settings. In the Netherlands, $92 \%$ of patients with dementia die in nursing or residential homes (10). In the UK General Practitioners were surveyed, as they often remain responsible for the care of the person with dementia.

In the Netherlands, we sampled one in four from an alphabetical list of surnames of the 1248 elderly care physicians who were members of the Dutch Association of Elderly Care Physicians and Social Geriatricians Verenso, and who were practicing in autumn 2012. The elderly care physician is the physician for frail elderly people and chronic diseases with complex disorders, no matter where they are living. The work area covers mostly nursing homes, but also residential homes, hospitals (transfer wards, outpatient wards as a consultant), the mental healthcare system (outpatient and clinical elderly care) or hospices.

Of the 316 self-complete postal surveys sent out in April 2013, 207 were returned and five were returned as undeliverable, resulting in a response rate of $66.6 \%$ (207/311). Nineteen 
of the 207 were excluded from the analyses as 13 had no experience with patients dying with dementia and returned the survey not completed as instructed, and six were not providing any clinical care currently due to illness or for other reasons; resulting with an adjusted sample of 188 respondents.

In order to target General Practitioners (GP) in the UK with responsibility for the care of elderly patients with dementia, a purposive, cluster sampling approach was used. Administrative data were used to create a sampling frame of GP group practices with a prevalence of 30 or more patients diagnosed with dementia in the past year (2011-2012). At the time of sampling (2013) there were 1176 GPs in Northern Ireland (NI), 765 of these had 30 or more dementia patients registered at their practice. A self-complete postal survey was sent to 340 GPs located across NI in 2013, this region that has identified the highest dementia diagnosis rates in the UK, (11), and represented 174 practices (49\% of all practices in NI). The response rate was $40.6 \%$ (138/340) representing $60.9 \%$ of the surveyed practices (106/174) from this response 129 surveys were complete and available for analyses.

\section{Measure}

The "Care for Dementia Patients at the End of Life" survey instrument explored physicians' perceptions on the acceptability of palliative care for individuals with dementia. The section of the instrument presented in this report examined respondent perceptions of the eleven elements identified by EAPC as the core domains for optimal palliative care for individuals living with dementia (Table 2). To ensure that each survey item would contain only one explicit concept, the first EAPC domain 'Applicability of palliative care' the was split into two items: a) Acceptance of professionals that palliative care applies to dementia, and b) Acceptance amongst the public that palliative care applies to dementia. We further selected access to specialist support as a relevant issue in the domain of societal and ethical issues (domain 11).

Respondents were asked to assess each item that represented an aspect of palliative dementia care, in its importance $(0=$ Not Important to $10=$ Very Important $)$; and how 
significant was the barrier to achieve this aspect of care in their clinical practice $(0=$ Not Significant to $10=$ Very Significant). We measured experience in dementia palliative care by asking for an estimation on the number of dying dementia patients cared for in the past year. We assessed physician and practice characteristics in some detail using the same items preparing for the cross-national comparison. The survey was translated from English into Dutch and we discussed and resolved any discrepancies with a back translation by a professional translator. The instrument was pretested on a local convenience sample of elderly care physicians in the Netherlands and GPs in NI.

\section{Data Management and Analyses}

Survey data was inputted and managed using Blaise (4.7.1, 2008, Statistics Netherlands, The Hague, Netherlands) and IBM SPSS Statistics 21. Responses to each survey item were graphed and frequencies examined using means and standard deviations. To examine the contrasts between physician perceptions in the two jurisdictions, t-tests were performed on the importance and barrier scores.

Ethical approval was obtained from the School Research Ethics Committee, School of Nursing and Midwifery, Queen's University Belfast. In the Netherlands, the study was approved by the Medical Ethics Review Committee of the VU University Medical Center. Receipt of a completed questionnaire implied consent.

\section{Results}

Table 1 describes the characteristics of the respondents and reveals notable differences between the Netherlands and NI (12). Female physicians made up $67.0 \%$ of the sample in the Netherlands and $42.6 \%$ in NI. The physicians in the two regions did not differ in terms of age, but the data referring to the characteristics of their practice, such as time spent in nursing homes and the number of patients treated for dementia, illustrate the different roles undertaken by the survey respondent physicians in the Netherlands and NI.

Insert Table 1 about here 
In the Netherlands, $90.4 \%$ of physicians reported spending $50 \%$ or more of their clinical time in nursing home settings. This is what we would expect because elderly care physicians in the Netherlands are generally employed by nursing homes. In contrast, $96.9 \%$ of the physicians in Northern Ireland reported spending a quarter or less of their clinical practice time in a nursing home setting. This is also as expected given that they are rarely co-located and therefore need to travel to nursing homes.

Results presented in Table 2 reveal that physicians in both jurisdictions consider all 12 aspects of care to be important (with means ranging from 8.0 - 9.5) except for prognosis, and in the Netherlands, specialist support. Treating symptoms; family involvement; and person centred care emerged as the three most important domains involved in delivering optimal palliative care in dementia in both the Netherlands and $\mathrm{NI}$, with efforts towards minimising aggressive treatment rating equally with involvement of family in the Netherlands. Minimising aggressive treatment is also considered of high importance in NI. Physicians in both jurisdictions also prioritise acceptance of the need for palliative care for dementia amongst professionals. These five aspects of care received average scores of nine or above, in both the Netherlands and NI. Table 2 reveals that respondents in NI placed significantly more importance than respondents in the Netherlands on efforts to promote Acceptance amongst the public that palliative care applies to dementia and the priority of Psychological and spiritual support. Accurate prognosis to allow for timely recognition of dying scored lowest in the priority list. The item revealing the highest contrast between the priorities of physicians in the Netherlands and NI was availability to specialist support in palliative care for dementia (Netherlands=7.3, $\mathrm{NI}=8.7$ ).

Insert Table 2 about here

Perceptions of the barriers to optimal practice were shared between respondents in the Netherlands and NI. Respondents in both $\mathrm{NI}$ and the Netherlands rated education and training specific to palliative care in dementia for the health care team and acceptance amongst the public that palliative care applies to dementia among the most important barriers to providing palliative care in dementia. In contrast, domains of care perceived to 
create less of a barrier were: acceptance amongst professionals that palliative care applies to dementia; treating symptoms; and psychological and spiritual support. There was a contrast in perceptions about barriers relating to specialist support between Netherlands and $\mathrm{NI}$ (Netherlands $=3.7, \mathrm{NI} 6.2$ ).

\section{Discussion}

In both Northern Ireland (NI) and the Netherlands, physicians agree that providing person centred care, with optimal communication and shared decision-making is fundamental to the delivery of optimal palliative care for patients with dementia. The three most important domains in both countries are treating symptoms for comfort, family involvement and person-centred care. This pattern mirrors and supports the expert opinion ratified by the European Association for Palliative Care recommendations (4).

The perceived barriers to providing optimal palliative care were shared by respondents in each country. There was more variability in ratings of barriers compared to importance. Generally the barriers were perceived to be lower in the Netherlands, when compared to NI. This finding is likely to be, at least in part, a product of the variation in the health care delivery systems in the two jurisdictions, characterised by the contrasting roles of the physicians with responsibility for dementia care. To elaborate, in NI the domain perceived as creating the greatest barrier in clinical practice was the availability of specialist support.

The physicians who care for nursing home patients with dementia in the Netherlands are generalists with a specialist certification in caring for frail and elderly patients (9). They spend at least half of their working week situated in residential and nursing home settings. In contrast the survey respondents in $\mathrm{NI}$ are qualified generalists who spend less than a quarter of their working week in nursing home settings. In the Netherlands, more time spent on site provides opportunities to communicate and connect with the wishes of members of the families involved in caring responsibilities. In contrast, in NI dementia care potentially remains fragmented (13), with the GP role limited in both contact time and access to specialist service provision $(14,15)$. 
Lack of education of professional teams and lack of awareness of the general public were among the most important barriers in both countries. In NI, the care of dementia patients in nursing and residential homes falls to the care of nursing and ancillary staff teams who are based on site, or in a crisis, care is provided at hospital. Therefore the physicians in NI may be suggesting that not only general practitioners but also those health care teams onsite in nursing homes may need more training specific to palliative care in dementia.

In the Netherlands, the emphasis on public perceptions as a barrier to implementation of optimal standards in palliative care for dementia suggests that physicians may feel that views of the public can occasionally thwart efforts to implement optimal care. This resonates with previous research findings in which physicians in the Netherlands reported taking the ultimate responsibility for difficult decisions about potentially invasive or futile medical interventions in dementia patients nearing the end of life. These decisions can contrast with the wishes of family members, but Dutch physicians express a strong sense of responsibility to act in the best wishes of the patient, even when this may conflict with the wishes of the family (16).

The current findings both support and enhance the new recommendations ratified by the EAPC (4) as well as findings of a review highlighting access to specialists, and a lack of time to devote to family and carer needs; conceptualised within doctor, system and patient barriers to providing timely diagnosis and effective management of dementia (15).

\section{Limitations}

The survey response rate in the Netherlands was reasonable, but in $\mathrm{NI}$ it was less than $50 \%$, which risks some response bias. Previous response analyses of GP survey research have indicated that fewer responses may be received from less qualified GPs and those who are not involved in training or members of the Royal College of General Practitioners (17), however the sampling approach adopted in the current study did not provide the appropriate data to make these comparisons. We found no evidence of response bias in terms of geography, population density or prevalence of dementia at the practice level. It should also be recognized that the survey reports physicians' perceptions of the acceptability of palliative care for people with dementia. This 
differs from a direct assessment of what the public, especially family members of people with dementia, say themselves about palliative care for dementia.

\section{Future directions}

To take forward implementation of the EAPC guidelines for palliative care for dementia it will be necessary to assess the challenges more thoroughly at a country-specific level and to design and test interventions that may include systemic changes, to help physicians to overcome such challenges.

In the Netherlands efforts should focus on person centred care involving optimal communication and shared decision making, public awareness and acceptance of palliative care for dementia and further exploration of the nature of the training and educational needs of healthcare professionals. Person centred care involving optimal communication and shared decision making should also be addressed in the Northern Ireland context, alongside additional specialist support, and initiatives encouraging family involvement. The shape of specialist provision in the Netherlands may provide a template to address the latter two concerns within the UK (NI) system.

This report provides the first steps of a road map for implementation of the EAPC endorsed palliative care guidelines for this vulnerable population with dementia. Future research focusing on other countries, other specialties and communication skills awareness and training for practitioners would provide useful additional guidance to take steps towards European and worldwide implementation of consistent improved end of life care for people with dementia. 


\section{References}

1. Prince M, Bryce R, Albanese E, Wimo A, Ribeiro W, Ferri CP. The global prevalence of dementia: a systematic review and metaanalysis. Alzheimer's \& dementia : the journal of the Alzheimer's Association. 2013;9(1):63-75.e2.

2. Zanetti O, Solerte SB, Cantoni F. Life expectancy in Alzheimer's disease (AD). Archives of Gerontology and Geriatrics. 2009;49 Suppl 1:237-43.

3. van der Steen JT. Dying with dementia: what we know after more than a decade of research. Journal of Alzheimer's Disease. 2010;22(1):37-55.

4. van der Steen JT, Radbruch L, Hertogh CM, de Boer ME, Hughes JC, Larkin P, et al. White paper defining optimal palliative care in older people with dementia: A Delphi study and recommendations from the European Association for Palliative Care. Palliative Medicine. 2014;28(3):197-209.

5. Sachs GA, Shega JW, Cox-Hayley D. Barriers to Excellent End-of-life Care for Patients with Dementia. Journal of General Internal Medicine. 2004;19(10):1057-63.

6. Blasi ZV, Hurley AC, Volicer L. End-of-life care in dementia: a review of problems, prospects, and solutions in practice. Journal of the American Medical Directors Association. 2002;3(2):57-65.

7. Luchins DJ, Hanrahan P. What Is Appropriate Health Care for End-Stage Dementia? Journal of the American Geriatrics Society. 1993;41(1):25-30.

8. Dillman D, Smyth J, Christian LH. Internet, Mail and Mixed-Mode Surveys: The Tailored Design Method. 3rd ed. Hoboken, New Jersey: John Wiley \& Sons; 2009.

9. Koopmans RTCM, Lavrijsen JCM, Hoek JF, Went PBM, Schols JMGA. Dutch Elderly Care Physician: a new generation of nursing home physician specialists. Journal of the American Geriatrics Society. 2010;58(9):1807-9.

10. Houttekier D, Cohen J, Bilsen J, Addington-Hall J, Onwuteaka-Philipsen BD, Deliens L. Place of death of older persons with dementia. A study in five European countries. Journal of the American Geriatrics Society. 2010;58(4):751-6.

11. UK Alzheimer's Society. Dementia diagnosis rates 2014 [3rd December 2015]. Available from:

http://www.alzheimers.org.uk/site/scripts/documents info.php?documentID=2165

12. van der Steen JT, Galway K, Carter G, Brazil K. Initiating advance care planning on end-of-life issues in dementia: Ambiguity among UK and Dutch physicians. Archives of Gerontology and Geriatrics. 2016;65:225-30.

13. Nolan M, Ryan T, Enderby P, Reid D. Towards a More Inclusive Vision of Dementia Care Practice and Research. Dementia. 2002;1(2):193-211.

14. Department of Health Social Services and Public Safety Northern Ireland. Improving Dementia Services in Northern Ireland 2011.

15. Koch $\mathrm{T}$, lliffe $\mathrm{S}$. Rapid appraisal of barriers to the diagnosis and management of patients with dementia in primary care: a systematic review. BMC Family Practice. 2010;11:52.

16. Helton MR, van der Steen JT, Daaleman TP, Gamble GR, Ribbe MW. A crosscultural study of physician treatment decisions for demented nursing home patients who develop pneumonia. Annals of Family Medicine. 2006;4(3):221-7.

17. Barclay S, Todd C, Finlay I, Grande G, Wyatt P. Not another questionnaire! Maximizing the response rate, predicting non-response and assessing non-response bias in postal questionnaire studies of GPs. Family Practice. 2002;19:105-11. 
TABLE 1. CHARACTERISTICS OF SURVEY RESPONDENTS IN THE NETHERLANDS AND NORTHERN IRELAND

\begin{tabular}{lcc}
\hline Characteristic & $\begin{array}{c}\text { Netherlands } \\
(\mathrm{n}=188 \text { elderly } \\
\text { care } \\
\text { physicians)* }\end{array}$ & $\begin{array}{c}\text { Northern } \\
\text { Ireland(n=129 } \\
\text { general } \\
\text { practitioners)* }\end{array}$ \\
\hline Gender & $\begin{array}{c}67.0 \% \text { Female } \\
48.4[9.2]\end{array}$ & $\begin{array}{c}42.6 \% \text { Female } \\
49.3[8.3]\end{array}$ \\
Mean age [SD] & $20.8[9.0]$ & $24.7[8.0]$ \\
Years in practice, mean [SD] & $3.63[1.0]$ & $2.77[0.8]$ \\
Dying patients with dementia in past year, mean [SD] & & \\
How often do you visit a typical nursing home patient? \% (n) & $63.8(118)$ & $3.1(4)$ \\
At least Daily & $24.3(45)$ & $48.4(62)$ \\
At least Weekly & $8.6(16)$ & $19.5(25)$ \\
At least Monthly & $3.2(6)$ & $17.2(22)$ \\
Every 2 months & 0 & $11.7(15)$ \\
Less than every 6 months & & \\
Percentage of clinical time spent in the nursing home, \% (n) & $3.7(7)$ & $57.4(74)$ \\
$<10 \%$ & $1.1(2)$ & $39.5(51)$ \\
10-24\% & $4.8(9)$ & $2.3(3)$ \\
$25-49 \%$ & $27.3(51)$ & $0.8(1)$ \\
$50-74 \%$ & $29.4(55)$ & 0 \\
$75-90 \%$ & $33.7(63)$ & 0 \\
$>90 \%$ & & \\
\hline
\end{tabular}

\footnotetext{
*Numbers will vary across questions due to missing values
} 


\begin{tabular}{|c|c|c|c|c|c|}
\hline \multicolumn{2}{|c|}{ Domains in the EAPC Ratified Guidelines } &  &  & $\begin{array}{l}\frac{n}{0} \\
\frac{1}{0} \\
\frac{1}{2} \\
\frac{1}{2} \\
\frac{1}{0} \\
2\end{array}$ & 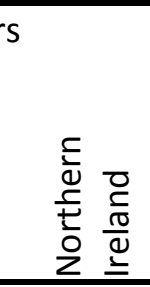 \\
\hline $1 \mathrm{a}$ & Acceptance amongst professionals that palliative care applies to dementia & $9.0(1.2)$ & $9.0(1.4)$ & $3.2(2.4)$ & $3.5(3.1)$ \\
\hline $1 b$ & Acceptance amongst the public that palliative care applies to dementia & $8.1(1.8)$ & $8.6 *(1.9)$ & $5.1(2.3)$ & $5.6(2.8)$ \\
\hline 2 & $\begin{array}{l}\text { Person-centred palliative care in dementia involving optimal communication and } \\
\text { shared decision making }\end{array}$ & $9.3(1.0)$ & $9.1(1.3)$ & $3.8(2.3)$ & $5.0^{+}(2.9)$ \\
\hline 3 & Setting care goals as part of producing advance care plans & $8.1(1.6)$ & $8.0(2.1)$ & $3.6(2.4)$ & $5.0^{+}(2.9)$ \\
\hline 4 & Continuity within palliative care in dementia & $8.5(1.4)$ & $8.5(1.6)$ & $4.4(2.6)$ & $5.7^{+}(2.9)$ \\
\hline 5 & Accurate prognosis to allow for timely recognition of dying & $7.3(1.8)$ & $7.5(2.3)$ & $3.9(2.4)$ & $5.1^{\dagger}(2.6)$ \\
\hline 6 & $\begin{array}{l}\text { Minimising aggressive, burdensome or futile treatment that will not extend life or } \\
\text { provide comfort }\end{array}$ & $9.2(1.2)$ & $9.0(1.5)$ & $4.1(2.4)$ & $5.6^{+}(3.0)$ \\
\hline 7 & Treatment and care of symptoms that is designed to provide comfort & $9.5(0.9)$ & $9.4(1.0)$ & $3.1(2.3)$ & $3.9 *(2.9)$ \\
\hline 8 & Psychological and spiritual support & $8.0(1.8)$ & $8.7^{\ddagger}(1.7)$ & $3.5(2.5)$ & $4.4^{\S}(3.0)$ \\
\hline 9 & Family involvement and associated support for families in caring for the patient & $9.2(1.0)$ & $9.3(1.0)$ & $3.4(2.4)$ & $5.5^{+}(2.9)$ \\
\hline 10 & Education and training specific to palliative care in dementia for the health care team & $8.3(1.4)$ & $8.6(1.6)$ & $5.0(2.5)$ & $5.7 *(2.7)$ \\
\hline 11 & Availability to specialist support in palliative care for dementia. & $7.3(2.2)$ & $8.7^{\dagger}(1.8)$ & $3.7(2.7)$ & $6.2^{+}(2.9)$ \\
\hline
\end{tabular}


TABLE 2. 'IMPORTANCE OF' AND 'BARRIERS INVOLVED' IN IMPLEMENTING OPTIMAL PALLIATIVE CARE FOR DEMENTIA, (AVERAGE SCORES (SD)) Between-country differences:

*T-test $p<0.05$

tT-test $p<0.0001$

\# T-test $p<0.001$

$\S$ T-test $p<0.01$ 